\title{
Equiatomic Ti-Cu alloys synthesized by powder metallurgy and melting techniques
}

N. Perez-Morales ${ }^{1}$, I. Estrada-Guel ${ }^{2}$, A. Torres-García ${ }^{3}$, M. Rocha-Rubio ${ }^{4}$, J.F. Hernández-Paz ${ }^{3}$, C.A. Rodríguez-González ${ }^{3}$ and C.D. Gómez-Esparza ${ }^{3}$

${ }^{1}$ Universidad Tecnológica de Ciudad Juárez, Ciudad Juárez, Chihuahua, Mexico, ${ }^{2}$ Centro de Investigación en Materiales Avanzados (CIMAV), Laboratorio Nacional de Nanotecnología, Miguel de Cervantes No. 120, CP 31136, Chihuahua, Chih., México., Chihuahua, Chihuahua, Mexico, ${ }^{3}$ Universidad Autónoma de Ciudad Juárez, Ciudad Juarez, Chihuahua, Mexico, ${ }^{4}$ Universidad Tecnológica de Ciudad Juárez, Ciudad Juarez, Chihuahua, Mexico

The use of Ti-Cu alloys has proven to have good results in the application of dental implants due to the bactericidal effect of $\mathrm{Cu}$ and the high corrosion resistance of this type of alloys [1]. For better performance of implants in terms of biocompatibility and antimicrobial response during service in the human body, the copper concentrations in Ti alloys must have an adequate proportion. On the other hand, despite the highbiocompatibility of $\mathrm{Ti}$, and the bactericidal effect of $\mathrm{Cu}$, the $\mathrm{Ti}-\mathrm{Cu}$ alloys have shown a deficiency in mechanical properties, which is reflected in particle release and consequently the formation of bacterial colonies. Through the powder metallurgy technique (PM) it is possible to produce Ti-based materials to obtain prototypes for biomedical application. Mechanical alloying is a process used in the PM from which nanocrystalline materials with improved mechanical properties can be obtained [2]. In this work, the synthesis of equiatomic Ti-Cu alloys by mechanical alloying and subsequent melting or sintering processes was performed to evaluate the hardness and microstructural features of alloys as a function of the consolidation process. Equiatomic Ti-Cu alloy was synthesized by mechanical alloying (MA) process from elemental $\mathrm{Ti}$ and $\mathrm{Cu}$ powders (Alfa Aesar, $\geq 99 \%$ ). The MA was performed under Ar atmosphere in hardened steel vial and grinding media for 5 and $10 \mathrm{~h}$. Bulk specimens were obtained by two different routes: a) melting under vacuum at $1000{ }^{\circ} \mathrm{C}$ and b) conventional sintering under vacuum at $850{ }^{\circ} \mathrm{C}$ for 3 $\mathrm{h}$. The powder and consolidated samples were characterized by X-ray diffraction, scanning electron microscopy, and microhardness test. In Fig. 1 SEM-SE micrograph and elemental mapping of Ti-Cu blended powders are shown; the $\mathrm{Cu}$ particles present a spherical morphology while Ti particles exhibit a flake-like shape. In Fig. 2 are presented SEM-BSE micrographs of Ti-Cu powders after 5 and $10 \mathrm{~h}$ of milling, homogeneous chemical composition of powder particles was detected. According to X-ray diffraction results, after $10 \mathrm{~h}$ of mechanical alloying, all the diffraction peaks corresponding to pure elements disappeared. The samples with $10 \mathrm{~h}$ of milling were selected for the subsequent consolidation processes. There is no evidence of a significant difference in the phase composition according to the type of consolidation process (smelting or sintering), but the crystal size is smaller for the sintered alloy. The microstructure of bulk samples is shown in the SEM-BSE micrographs of Fig. 3. Both consolidation processes are conducted to the formation of a microstructure with phases with a similar chemical composition. For both samples, the brightest phase has a Ti content of about $36 \%$ (wt.\%), while the darkest phase contains about $75 \mathrm{wt} . \%$ Ti. The mean values of microhardness were $845 \mathrm{HV}$ for the sintered sample, and 719 for the as-cast sample. The consolidation process has a significant effect on the hardness of bulk samples. The MA process produced nanocrystalline powder alloy, and it is suggested that the sintering process prevents excessive grain growth in comparison to the melting route. 
$\mathrm{Ti} \mathrm{K} \alpha 1$
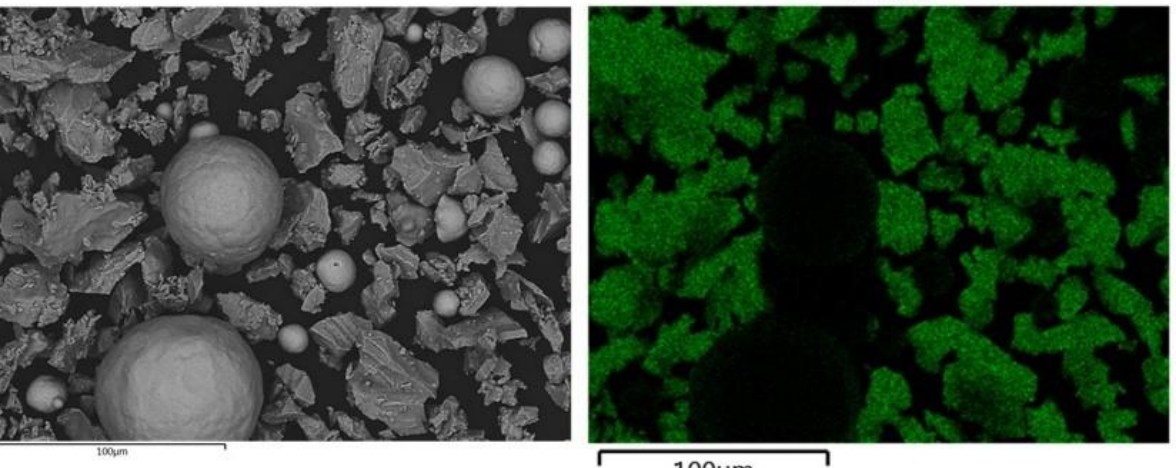

$100 \mu \mathrm{m}$
$\mathrm{Cu} \mathrm{K} \alpha 1$

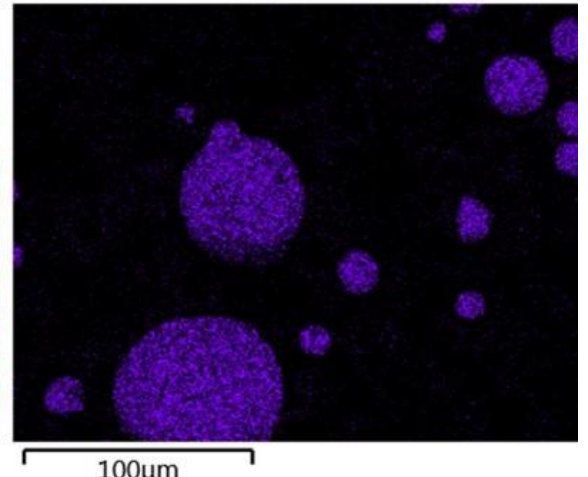

$100 \mu \mathrm{m}$

Figure 1. Figure 1. SEM-SE micrograph and elemental mapping of equatomic Ti-Cu blended powder.

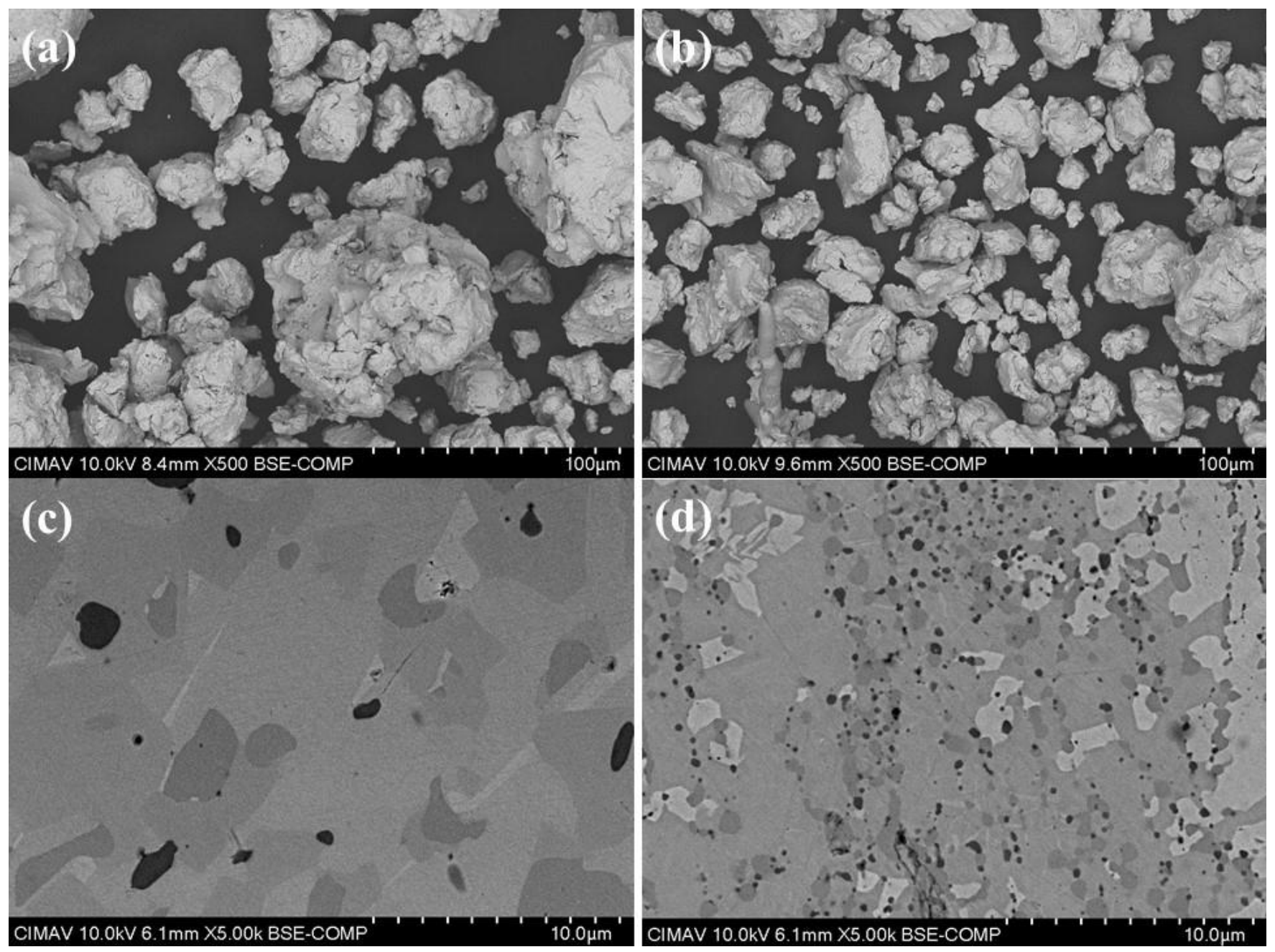

Figure 2. Figure 2. SEM-BSE micrographs of Ti-Cu powders after: a) 5 and b) $10 \mathrm{~h}$ of milling; and Ti$\mathrm{Cu}$ consolidated samples by: c) melting and d) sintering processes.

References

[1] O.J. Lee Fowler, S.N. Håkan-Engqvist, C. Öhman-Mägi, Mater. Sci. Eng. C 97 (2019) p. 707.

[2] L. Bolzoni, F. Yang, J. Mech. Behav. Biomed. Mater. 97 (2019) p. 41. 